\title{
Condition Monitoring of Distribution Transformer using IOT
}

\author{
Amol A. Sonune \\ Dept. of Electrical Engg \\ SSGMCE, Shegaon. \\ Ankit A. Akotkar \\ Dept. of Electrical Engg \\ SSGMCE, Shegaon.
}

\author{
Mayur S. Talole \\ Dept. of Electrical Engg \\ SSGMCE, Shegaon. \\ Piyush S. Jaiswal \\ Dept. of Electrical Engg. \\ SSGMCE, Shegaon.
}

\author{
Sumit V. Sonkusale \\ Dept. of Electrical Engg. \\ SSGMCE, Shegaon. \\ Vivek N. Gayki \\ Dept. of Electrical Engg. \\ SSGMCE, Shegaon.
}

\begin{abstract}
Distribution transformers are one of the most important equipment in power network. Because of, the large number of transformer distributed over a wide area in power electric system, the data acquisition and condition monitoring is a important issue. To monitor this operator has to visit to transformer location itself. The main aim of this system is to monitoring the distribution transformer parameter like load current, voltage, oil level and oil temperature using IOT. So using this it can minimize working efforts and improve accuracy, stability and efficiency. Sensors are used to sense the main parameters of equipment such as voltage, current, temperature and oil level, this sensed data is sent to ESP 32 microcontroller. ESP 32 is a series of low cost, low power on a chip microcontroller with integrated $\mathrm{Wi}-\mathrm{Fi}$ and dual mode Bluetooth. So, there is no need to connect Wi-Fi module externally, hence size of project is also small. This controller checks parameter limits which further send to the IOT web server Blynk software using Wi-Fi module of these data makes sure the right information is in hand to the operator and operator can make useful decisions before any catastrophic failure on basis of that data of parameters.
\end{abstract}

Keywords- IOT (Internet of Things); ESP 32; temperature sensor; voltage sensor; current sensor; ultrasonic sensor, distribution transformer.

\section{INTRODUCTION}

Internet of things (IOT) is the inter-networking of physical devises vehicles (also referred to as "connected devise" and "smart devices"). Buildings and other items embedded with electronics, software, sensors, actuators, and network connectivity that enable these objects to collect and exchange data.

IOT allows objects to be sensed or controlled remotely across existing network infrastructure, creating opportunities for more direct integration of the physical world into computer base system, and resulting in improved efficiency, accuracy and economic benefit in addition to reduced human intervention.

Distribution transformers have long service like if they operated under good and rated conditions. However, their life is significantly reduced if they are overloaded, resulting an unexpected failures and loss of supply to a large number of customers thus effecting system reliability. Overloading and ineffective cooling of transformer are the measure causes of failure in distribution transformer. Most power companies uses Supervisory Control and Data Acquisition (SCADA) system for online monitoring of power transformer but extending the SCADA system for online monitoring of distribution transformer is an expensive proposition. Distribution transformers are currently monitored manually where a person periodically visits to a transformer site for maintenance and records parameter of importance. This type of monitoring cannot provide information about occasional overloads and overheating of transformer oil and windings. All these factors can significantly reduce transformer life.

Our system is designed is based upon online monitoring of key operational parameters can provide useful information about the health of transformer which will help the utilities to optimally use their transformer and keep the asset in operation for longer period. This system will help us to identify problems before any catastrophic failure, thus resulting in a long life service for transformer.

This system is based upon the embedded system as self- contained program that are embedded within a piece of hardware. Embedded system are usually set to a specific task, another of thinking of an embedded system is as a computer system that is created with optimal efficiency, thereby allowing it to complete specific functions as quickly as possible. It is also has the advantages of significant cost saving, power consumption and greater reliability.

\section{BLOCK DIAGRAM}

Below figure shows the schematic block diagram of setup. Sensors are connected to the distribution transformer and ESP32. Voltage, current, oil level and oil temperature are continuously sensed by respective sensors and sensed data are send to the ESP 32 where it calculate sensed data as per the programming done in it, then it sends data to the blynk app via Wi-Fi. Blynk app has to be installed in our mobile, where we can continuously monitor all the parameters. If any parameter exceeds beyond its threshold value due to any abnormality in transformer then operator will received SMS through GSM. 


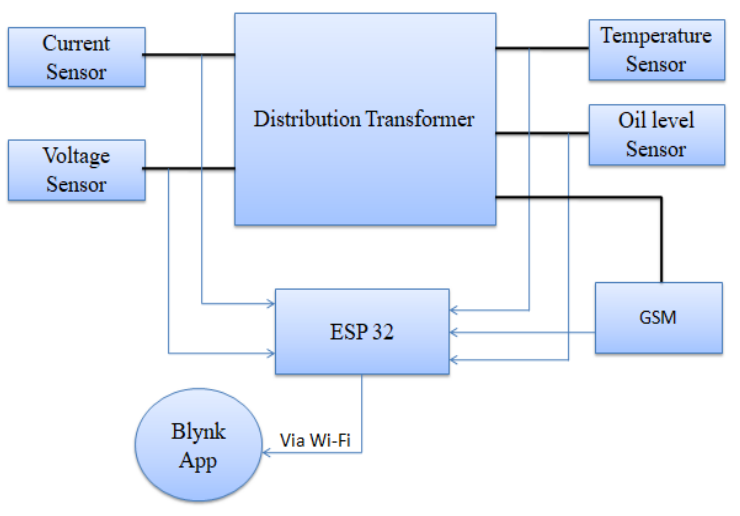

Fig.1- Block Diagram

III. HARDWARE ASPECTS.

A. CURRENT SENSING-

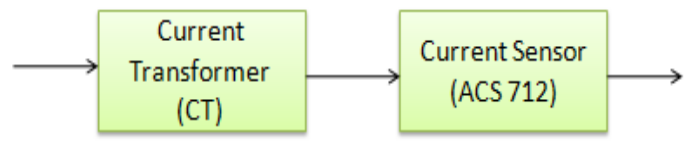

Fig.2- Current Sensing Block Diagram.

1. Current Transformer:-

As current of distribution transformer is in hundred of amperes. Hence current transformer step down the current value, so it can be measured by current sensor ACS 712.

2. Current Sensor (ACS712):-

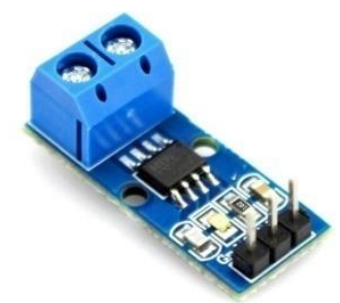

Fig.3- Current Sensor ACS712

The Allegro ACS712 provides economical and precise solutions for AC or DC current sensing in industrial, commercial, and communications system. Typical application includes motor control, load detection and management, switch mode power supplies and overcurrent fault protection.

B. Voltage SENSING:-

As secondary voltage of distribution transformer is single phase $230 \mathrm{~V}$, so it can be easily measure with the help of ZMPT101B AC voltage sensor.

ZMPT101B a voltage transformer ideal to measures the AC voltage. It has a high accuracy, good consistency for power measurement up to $250 \mathrm{~V} \mathrm{AC}$. Easy to use and comes with a multi turn trim potentiometer for adjusting the ADC output.

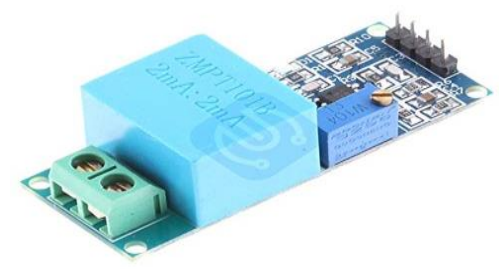

Fig.4- AC Voltage Sensor ZMPT101B.

\section{TEMPERATURE MEASUREMENT:-}

The principle of operation of PT100 platinum thermometer is to measure the resistance of platinum element. A 3 wire RTD PT100 temperature sensor can measure the temperature over a wide range of $-200^{\circ} \mathrm{C}$ to $850^{\circ} \mathrm{C}$. It measures the temperature of oil in the conservator tank by simply inserting it in the oil.

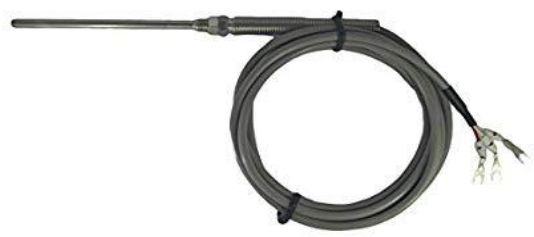

Fig.5- PT100 RTD 3 Wire Temperature Sensor.

\section{OIL LEVEL MEASUREMENT:-}

Oil level sensor is a device which is used to check the oil level in the transformer's conservator tank. JSN-SR0T4-2.0 ultrasonic distance measurement module provides $20 \mathrm{~cm}$ to $600 \mathrm{~cm}$ non-contact distance sensing function, ranging accuracy up to $2 \mathrm{~mm}$. This sensor is provides with a integrated closed waterproof cable probe, suitable for wet, bad measurement occasion.

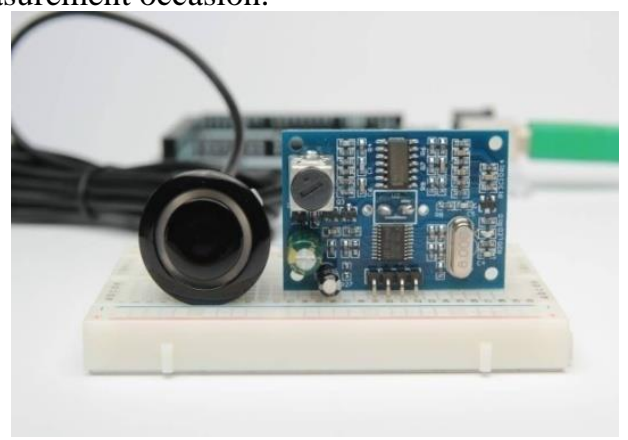

Fig.6- Ultrasonic Sensor JSN-SR0T4-2.0

E. ESP 32:-

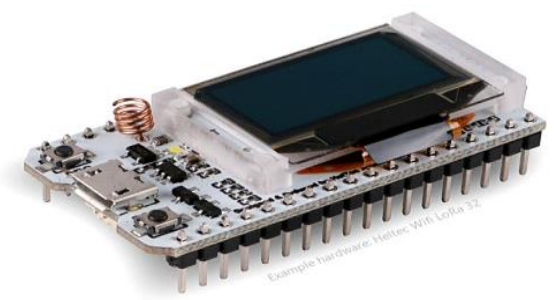

Fig.7- Wi-Fi Lora ESP32 
ESP32 is a series of low cost, low power system on a chip microcontroller with integrated $\mathrm{Wi}-\mathrm{Fi}$ and dual mode Bluetooth. The ESP32 series employs a Tensilica Xtensa LX6 microprocessor in both dual core and single core variations includes built in antenna switches, RF balun, power amplifier, low noise receive amplifier, filters, and power management modules. Voltage, current, temperature and oil level are sense in analog form and converted into digital using respective sensors and then sensed data is fed to the ESP 32. Below diagram shows pin diagram of Wi-Fi Lora ESP 32.

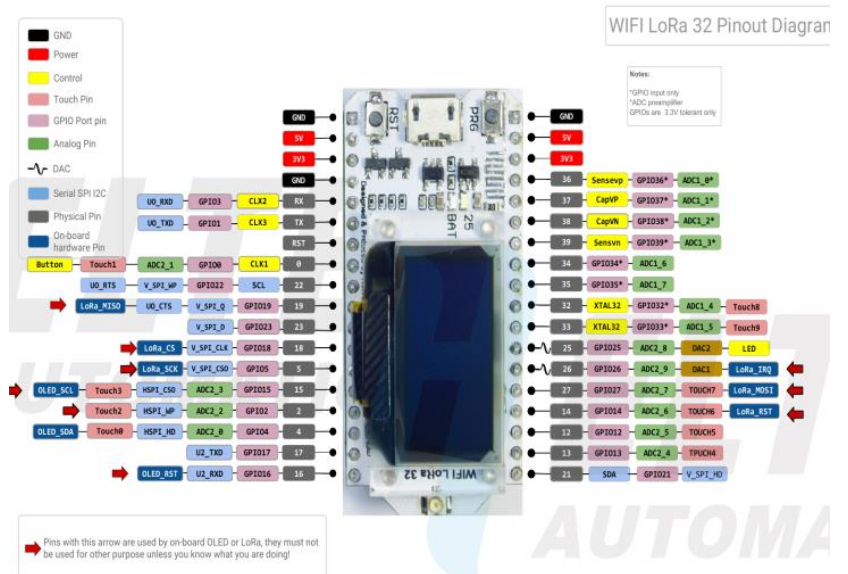

Fig.8- Pin Diagram of Wi-Fi Lora ESP 32

\section{F. GSM MODULE:-}

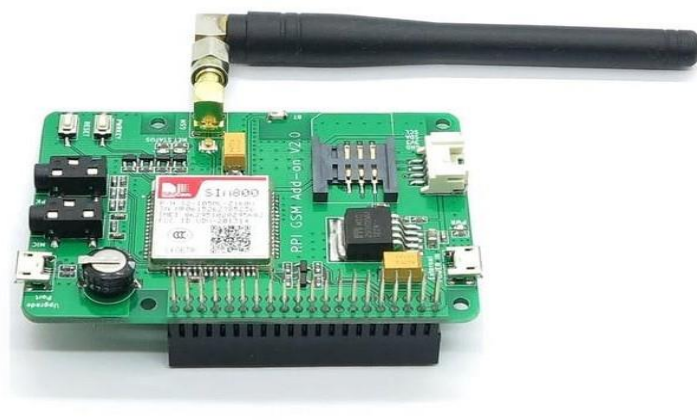

Fig- GSM Module

GSM module is used to establish connection between a computer GSM-GPRS system. Global System for Mobile Communications (GSM) is an architecture used for mobile communication in most of the countries. GSM module is consists of a GSM modem assembled together with power supply circuit and communication interfaces for computer.

\section{SOFTWARE ASPECTS}

Using the microcontroller native language, a software algorithm is developed in Arduino IDE software which is an open source app where one can code, compile and upload a file in any arduion device. The algorithm is start by initializing the input output ports data direction flow. Then it begins to command the sequence according to the algorithm. It continuously checks voltage, current, temperature and oil level reading and sends to blynk app via Wi-Fi. Blynk app is open source app where operator monitored data at any time and any place. If any parameter value exceeds beyond its threshold value then through GSM operator get message immediately on mobile, so he can take suitable action.

\section{RESULT}

This introduces a new and improves method of transformer parameter monitoring using IOT. Sensors incorporated in the system collect the data of transformer. Main parameters of equipment such as voltage, current, temperature and oil level. This sensed data is send to ESP32 and this controller checks parameter limits which further sent to the IOT web server Blynk software using Wi-Fi module. Thus the real time data monitoring are possible with the system.

\section{CONCLUSION}

The IOT based monitoring of distribution transformer is quite useful as compared to manual monitoring and also it is reliable as it is not possible to monitor always the voltage, current, oil level and temperature rise manually. If any abnormality occurs operator gets a message so we can take action to prevent any failures of distribution transformers, thus we can recover the system in less time and faults before any uncertain failures. Thus this system is cost saving and as controller that we used has small size compared to other controller, the overall size of whole setup is also small.

\section{ACKNOWLEDGMENT}

We would like to express our deepest appreciation to all those who provided us the possibility to complete this report. It would not have been possible without the help and guidance of various people throughout the making of this work. A special gratitude we to our guide, Dr. S. S. Jadhao, for his excellent guidance throughout this work. We are highly indebted to him for his guidance and constant supervision as well as for providing necessary information from time to time. We owe our deep gratitude to Dr. S. R. Paraskar, HOD of Dept. Of Electrical Engineering, and Dr. S. B. Somani, Principal, Shri Sant Gajanan Maharaj College of Engineering, Shegaon for their blessings, encouragement and providing us the necessary support. We express our sincere esteems to our colleagues who helped willingly in completion of this work

\section{REFERENCES}

[1] Mrs. A. P. Khandait, Swapnil Kadaskar, Girish Thakare, "Real Time Monitoring of Transformer using IOT," International Journal of Engineering Research \& Technology (IJERT), ISSN:2278-0181

[2] http://www.allegromicro.com/en/Products/Current-SensorICs/Zweo-To-Fifty-Amp-Integrated-Conductor-SensorICs/ACS712.aspx

[3] http://www.espressif.com/en/products/socs/esp32/overview 


\section{AUTHORS PROFILE}

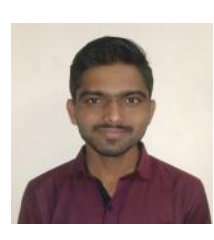

Amol A. Sonune

Bachelor of Electrical

Engineering,

(2017-2020), Shri Sant Gajanan

Maharaj College of Engineering, Shegaon (M.H.)

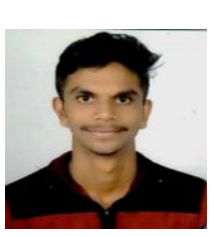

\section{Ankit A. Akotkar}

Bachelor of Electrical

Engineering,

(2017-2020), Shri Sant Gajanan Maharaj College of Engineering, Shegaon (M.H.)

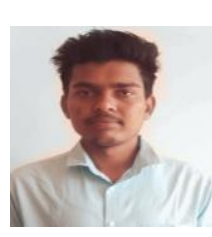

Mayur S. Talole

Bachelor of Electrical

Engineering,

(2017-2020), Shri Sant Gajanan Maharaj College of Engineering, Shegaon (M.H.)

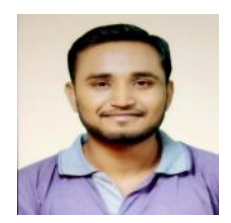

Piyush S. Jaiswal

Bachelor of Electrical

Engineering,

(2017-2020), Shri Sant Gajanan

Maharaj College of Engineering, Shegaon. (M.H.)

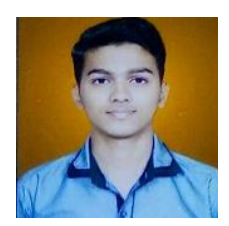

\section{Sumit V. Sonkusale}

Bachelor of Electrical

Engineering,

(2017-2020), Shri Sant Gajanan Maharaj College of Engineering, Shegaon. (M.H.)

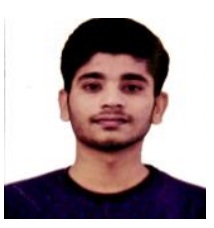

\section{Vivek N. Gayki}

Bachelor of Electrical

Engineering,

(2017-2020), Shri Sant Gajanan Maharaj College of Engineering, Shegaon. 